\title{
Correspondence
}

TO THE EDITOR, British Journal of Venereal Diseases

\section{Management of non-specific urethritis in men}

Sir,

Dr Evans's criticism 1 of one aspect of our paper $^{2}$ is well taken but was made slightly out of context. Taking the whole sample first, we had already found that " of the 143 patients who were retreated $66(46 \cdot 2 \%)$ admitted to unprotected sexual intercourse compared with $103(27 \cdot 5 \%$ of 375$)$ who did not require retreatment. This difference was significant $\left(\chi_{1}^{2} 15 \cdot 607 ; p<0 \cdot 001\right)$." The "sub-sample" of 112 provided further confirmation of this point as well as evidence (not acceptable to Dr Evans) as regards the effect of treatment of female sexual contacts on the retreatment rate of men. We did not claim these 112 men to be a statistical sample of the whole nor did we choose our couples. We simply included all

TO THE EDITOR, British Journal of Venereal Diseases

Future planning of venereological services

Sir,

Regional health authorities are considering the future of their venereology services. In the Northern Regional Strategic Plan $(1979-88)$ it is noted that in 1977 the mean number of new patients per session in their clinics was 3.5 and the mean total patients per session was $12 \cdot 2$ compared with $7 \cdot 0$ and 23.0 respectively for England as a whole. From these figures the authors of the Plan concluded that "the workload figures do not suggest that additional clinic provision should be considered at present."

These workload figures were obtained from the SH3 returns, the forms submitted monthly by clinics stating the numbers of sessions, new patients, and total attendances.

Study of the clinic time-tables in 1977, which have since been rationalised, couples who could be identified. We then made comparisons within this so-called sub-sample between two categories-that is, those requiring retreatment and those not requiring retreatment-and found that the difference was significantly related to sexual intercourse. We observed that sexual intercourse did not make any difference to the outcome of treatment with the singledose doxycycline regimen. But the pattern of treatment failure with all other regimens in this respect was different (Table $3^{2}$ ). We, therefore, consider the comparison between the sub-sample of 112 and the total sample of 562 to be irrelevant, especially in so far as it does not invalidate the comparisons within the sub-sample already mentioned.

As regards Dr Evans's suggestion of delayed failures, Dr Evans certainly knows that the longer the follow up the greater the chances of further sexual intercourse taking place and hence reinfection occurring. (Indeed as many as $71 \%$ of the patients retreated after five weeks in this study were associated with sexual intercourse.) If a venereologist does not recognise this fact then some contacts will remain untreated, thus contributing to a further spread of this $\frac{\bar{O}}{\bar{\omega}}$ sexually transmitted disease.

Finally, most of the retreatments took $\stackrel{\nabla}{\square}$ place between two and six weeks after completion of the initial regimen.

Yours faithfully,

O P Arya $C D$ Alergant $\omega$

E H Annels os

$P$ B Carey

A K Ghosh oु

A D Goddard î

Royal Liverpool Hospital, Liverpool L7 8XP

\section{References}

1. Evans B. Letter: Management of nonspecific urethritis in men. $B r J$ Vener Dis 1979; 55: 305.

2. Arya OP, Alergant CD, Annels EH, Carey PB, Ghosh AK, Goddard AD. Management of non-specific urethritis in men: Evaluation of six treatment regimens and effect of other factors including alcohol and sexual intercourse. Br J Vener Dis 1978; 54: 414-21. indicates several factors which contributed to the lower than average number of new patients and total attendances per session. Throughout the region the mean duration of a session was just under two hours $(1 \cdot 95)$. In one sea-port clinic there was only one two-hour session per week, and this was for women only. At another clinic, male and female patients were seen at separate times, six of their sessions per week were of one hour's duration, five of one and a half hours, and one of two hours' duration, but the clinic reported having 12 sessions per week for the $151 / 2$ hours it was open. Yet another clinic reported that it held 26 sessions per week, when in fact it was only open for 22 . In addition, in 1977 , 13 dual (where one doctor saw male and female patients) sessions per week were carried out by one doctor, although they were reported as 26 sessions. This grossly underestimated these doctors' worl:loads, and they were only paid for 13 sessions.

Happily it appears that only the numbers of new patients are being used to judge workload, although a good case could be made out for considering the number of 3 conditions diagnosed and treated. Total attendances would not be a good guide to workload because, between clinics, there $\frac{1}{4}$ are such wide variations in the number of $=$ post-treatment attendances required for $\frac{\sigma}{3}$ any one condition, and whereas some clinics record an attendance for each $\bigcirc$ condition, others record just one attendance irrespective of the number of 0 conditions that have been treated.

If workload, as reported in the $\mathrm{SH} 3 \frac{\mathrm{D}}{\mathrm{O}}$ returns, is to be the criterion on which the future of the venereology service is to be $N$ planned, then physicians in charge of clinics should ensure that sessions of short? duration are not reported as though they $\omega$ were full notional ones and that when one doctor carries out a dual session it is recorded as one and not two sessions.

Yours faithfully, C B S Schofield?

Newcastle General Hospital, Westgate Road,

Newcastle upon Tyne, NE4 6BE 